\title{
ANALISIS RESIKO PADA BAGIAN PRODUKSI PABRIK PENGOLAH GETAH KARET MENGGUNAKAN METODE HIRARC (Studi Kasus PT X Kota Padang)
}

\author{
Tivany Edwin ${ }^{1}$, Rinda Andhita Regia ${ }^{1}$, Mohammad Irfan $^{1}$ dan Yogi Kurniawan ${ }^{1}$ \\ ${ }^{1}$ Jurusan Teknik Lingkungan, Universitas Andalas, Kampus Unand Limau Manis Padang 25163, Indonesia \\ E-mail: tivany@eng.unand.ac.id, rindaandhita@gmail.com,mohammad29irfan@gmail.com \\ yogikurniawan@gmail.com
}

\begin{abstract}
ABSTRAK
PT X merupakan sebuah perusahaan yang bergerak di bidang pengolahan getah karet menjadi karet remah di Kota Padang. Beberapa kejadian kecelakaan kerja masih ditemukan pada kegiatan produksi pabrik ini. Untuk itu penting untuk dilakukan identifikasi bahaya, penilaian resiko dan menentukan jenis pengendalian resiko pada bagian produksi tertama pada bagian yang sering ditemukan terjadinya kecelakaan kerja PT X, salah satu cara dengan menggunakan Metode HIRARC. Analisis risiko dilakukan dengan mengalikan peluang dan tingkat keparahan terjadinya bahaya pada proses pengolahan raw material, penjemuran blanket dan pengolahan blanket di dryer. Hasil menunjukkan tidak terdapatnya tingkat risiko tinggi pada proses tersebut. Tingkat proses rendah ditemukan pada proses transfer dengan forklft, selebihnya merupakan tingkat resiko sedang. Pengendalian yang disarankan berupa rekayasa teknik, pengendalian adminitratif serta penggunaan Alat Pelindung Diri (APD).
\end{abstract}

Kata Kunci: Pabrik pengolah getah karet, Bahaya, Risiko, Pengendalian

\begin{abstract}
$P T X$ is a company engaged in processing rubber gum into crumb rubber. Several incidents of work accidents are still found in the factory's production activities. For this reason, it is important to identify hazards, risk and determine the type of risk control in the production section that is often found in the occurrence of PT X work accidents, by using the HIRARC Method. Risk analysis is done by multiplying the probability and severity of the occurrence of hazards in the processing of raw materials, drying blankets and processing of blankets on the dryer. The results showed that there found no high risk level in the process. Low process level was found in the transfer process with forklft, the rest of activity were in the moderate risk level. The recommended controls are engineering, administrative controls and the use of personal protective equipment.
\end{abstract}

Keywords: Rubber mills, Hazards, Risks, Controls

\section{PENDAHULUAN}

PT X merupakan sebuah perusahaan yang bergerak di bidang pengolahan getah karet menjadi karet setengah jadi. Kapasitas produksi dari PT X sebanyak 36.000 ton/tahun. Perusahaan ini memiliki 178 karyawan, Pabrik ini didirikan bertujuan untuk mengolah getah karet menjadi karet remah. Karet remah ini merupakan barang setengah jadi sehingga perlu pengolahan lanjutan agar bisa digunakan dan dimanfaatkan. Tahap produksi karet remah PT X terbagi menjadi lima proses yakni penerimaan bahan baku, milling (dikenal dengan proses basah), dryer, finish good (penyimpanan) dan shipping. Karet remah yang dihasilkan oleh PT X diekspor ke berbagai tempat dan ke berbagai negara seperti China, Singapura, Malaysia dan lain lain. Beberapa kejadian kecelakaan kerja masih ditemukan pada kegiatan produksi pabrik ini.

Kejadian kecelakaan kerja tidak terlepas dari seberapa baiknya penerapan Sistem Manajemen Keselamatan dan Kesehatan Kerja (SMK3) pada suatu perusahaan (Silalahi, 1991). SMK3 adalah bagian dari sistem manajemen perusahaan secara keseluruhan dalam rangka pengendalian risiko yang berkaitan dengan kegiatan kerja guna 
terciptanya tempat kerja yang aman, efisien dan produktif (Suma'mur 2013). Tujuan keselamatan kerja adalah melindungi tenaga kerja atas hak keselamatannya dalam melakukan pekerjaan untuk kesejahteraan hidup, meningkatkan produksi serta produktivitas perusahaan, menjamin keselamatan setiap orang lain yang ada di tempat kerja, serta memelihara dan menggunakan sumber produksi secara aman dan efisien (Sucipto, 2014). Di Indonesia, penerapan SMK3 diatur dalam Peraturan Pemerintah Nomor 50 Tahun 2012 tentang penetapan kebijakan Keselamatan dan Kesehatan Kerja (K3), perencanaan K3, pelaksanaan rencana $\mathrm{K} 3$, pemantauan dan evaluasi kinerja K3 serta peninjauan dan peningkatan kinerja SMK3.

Identifikasi bahaya adalah upaya sistematis untuk mengetahui potensi bahaya yang ada di lingkungan kerja. Dengan mengetahui sifat dan karakteristik bahaya, maka dapat lebih berhati-hati dan waspada dalam melakukan langkah-langkah pengamanan agar tidak terjadi kecelakaan, namun tidak semua bahaya dapat diketahui dengan mudah.Menurut Soehatman Ramli (2013) penilaian risiko mencakup 2 tahap proses yaitu menganalisis risiko (risk analysis) dan mengevaluasi risiko (risk evaluation). Analisis risiko adalah menentukan besarnya suatu risiko yang merupakan kombinasi antara kemungkinan terjadinya bahaya (likelyhood) dan tingkat keparahan (severity).

Metode yang digunakan salah satunya adalah metode HIRARC (Hazard Identification, Risk Assesment, and Risk Control). Metode ini terdiri dari serangkaian implementasi K3 dimulai dengan perencanaan yang baik meliputi identifikasi bahaya, memperkirakan risiko, dan menentukan langkah-langkah pengendalian berdasarkan data yang dikumpulkan dalam rangka untuk memperoleh model HIRARC komprehensif untuk kekuatan studi (Budiono dkk, 2003). Metode HIRARC inilah yang menentukan arah penerapan K3 dalam perusahaan sehingga perusahaan nantinya akan dapat menyelesaikan masalahnya sendiri, terutama masalah manajemen dalam perusahaan tersebut.

Untuk itu penting untuk dilakukan identifikasi bahaya, penilaian resiko dan menentukan jenis pengendalian resiko pada bagian produksi tertama pada bagian yang sering ditemukan terjadinya kecelakaan kerja PT X agar kecelakaan kerja dapat diturunkan frekuensinya.

\section{METODOLOGI PENELITIAN}

Identifikasi bahaya pada pabrik karet PT X dilakukan dengan wawancara mendalam. Identifikasi bahaya, peniliaan resiko dan penentuan pengendalian hanya difokuskan pada bagian yang sering ditemukan terkadinya kecelakaan kerja. Metode yang dipakai untuk identifikasi bahaya adalah Hazard Identification, Risk Assessment and Risk Control (HIRARC).

Penilaian risiko dapat dilakukan setelah proses analisis risiko dan evaluasi risiko selesai dilakukan secara keseluruhan. Analisis risiko dilakukan untuk mendapatkan perbandingan antara risiko kecil dengan risiko besar yang akan terjadi. Analisis risiko dilakukan untuk memperkirakan risiko dengan mengalikan nilai faktor peluang (likelihood) yang dapat dilihat pada Tabel 1, dan tingkat keparahan (consequence) yang telah didapatkan dari proses identifikasi bahaya. Penilaian tingkat keparahan dapat dlihat pada Tabel 2.

Tabel 1. Metode Penilaian Risiko Berdasarkan Peluang (Likelihood)

\begin{tabular}{cll}
\hline Tingkat & \multicolumn{1}{c}{ Uraian } & \multicolumn{1}{c}{ Keterangan } \\
\hline A & Hampir Pasti Terjadi & $\begin{array}{l}\text { Dapat terjadi setiap saat dalam kondisi normal, misalnya kecelakaan pada } \\
\text { lalu lintas yang padat }\end{array}$ \\
\hline B & Sering Terjadi & Terjadi beberapa kali dalam periode tertentu, misalnya kecelakaan kereta api \\
\hline C & Dapat Terjadi & $\begin{array}{l}\text { Risiko dapat terjadi, namun tidak sering, misalnya jatuh dari ketinggian } \\
\text { lokasi konstruksi }\end{array}$ \\
\hline D & Kadang-Kadang & Kadang-kadang terjadi, misalnya kebocoran pada instalasi nuklir \\
\hline E & Jarang Sekali & Dapat terjadi dalam keadaan tertentu, misalnya orang disambar petir \\
\hline
\end{tabular}


Tabel 2. Metode Penilaian Risiko Berdasarkan Keparahan (Severity)

\begin{tabular}{cll}
\hline Tingkat & \multicolumn{1}{c}{ Uraian } & \multicolumn{1}{c}{ Keterangan } \\
\hline $\mathbf{1}$ & Tidak Signifikan & Kejadian tidak menimbulkan kerugian bisnis dan cedera pada manusia \\
\hline $\mathbf{2}$ & Kecil & $\begin{array}{l}\text { Menimbulkan cedera ringan, kerugian kecil, dan tidak menimbulkan dampak } \\
\text { serius terhadap kelangsungan bisnis }\end{array}$ \\
\hline $\mathbf{3}$ & Sedang & $\begin{array}{l}\text { Cedera berat dan dirawat di rumah sakit, tidak menimbulkan cacat tetap, } \\
\text { kerugian finansial sedang }\end{array}$ \\
\hline $\mathbf{4}$ & Berat & $\begin{array}{l}\text { Menimbulkan cedera parah dan cacat tetap dan kerugian finansial besar serta } \\
\text { menimbulkan dampak serius terhadap kelangsungan usaha }\end{array}$ \\
\hline $\mathbf{5}$ & Bencana & $\begin{array}{l}\text { Mengakibatkan korban meninggal dan kerugian parah, bahkan dapat } \\
\text { menghentikan kegiatan usaha selamanya }\end{array}$ \\
\hline
\end{tabular}

Sumber : Ramli, 2013

Tabel 3. Matriks Kombinasi Peluang dan Keparahan

\begin{tabular}{cccccc}
\hline $\mathbf{P}$ & $\mathbf{1}$ & $\mathbf{2}$ & $\mathbf{3}$ & $\mathbf{4}$ & $\mathbf{5}$ \\
\hline $\mathbf{A}$ & $\mathrm{T}$ & $\mathrm{T}$ & $\mathrm{E}$ & $\mathrm{E}$ & $\mathrm{E}$ \\
\hline $\mathbf{B}$ & $\mathrm{S}$ & $\mathrm{T}$ & $\mathrm{T}$ & $\mathrm{E}$ & $\mathrm{E}$ \\
\hline $\mathbf{C}$ & $\mathrm{R}$ & $\mathrm{S}$ & $\mathrm{T}$ & $\mathrm{E}$ & $\mathrm{E}$ \\
\hline $\mathbf{D}$ & $\mathrm{R}$ & $\mathrm{R}$ & $\mathrm{S}$ & $\mathrm{T}$ & $\mathrm{E}$ \\
\hline $\mathbf{E}$ & $\mathrm{R}$ & $\mathrm{R}$ & $\mathrm{S}$ & $\mathrm{T}$ & $\mathrm{T}$ \\
\hline
\end{tabular}

Sumber : Ramli, 2013

Keterangan: E : Ekstrim,R : Rendah, S : Sedang, T: Tinggi

Tabel 4. Tabel Tingkatan Prioritas Pengendalian Risiko

\begin{tabular}{|c|c|c|}
\hline Risiko & Deskripsi & Aksi/ Tindakan \\
\hline $15-25$ & Tinggi & $\begin{array}{l}\text { Resiko tinggi yang memerlukan penatalaksanaan segera } \\
\text { untuk mengendalikan bahaya sesuai dengan hirarki } \\
\text { pengendalian. Tatalaksana yang diambil tersebut harus } \\
\text { didokumentasikan pada formulir penilaian resiko, } \\
\text { termasuk tanggal penyelesaian. }\end{array}$ \\
\hline $5-12$ & Sedang & $\begin{array}{l}\text { Risiko sedang yang memerlukan pencapaian terencana } \\
\text { untuk mengendalikan bahaya dan mengaplikasikan } \\
\text { perhitungan sementara bila diperlukan. Tata laksana yang } \\
\text { diambil tersebut harus didokumentasikan pada formulir } \\
\text { penilaian resiko, termasuk tanggal penyelesaian. }\end{array}$ \\
\hline $1-4$ & Rendah & $\begin{array}{l}\text { Suatu resiko yang digolongkan rendah dapat } \\
\text { dipertimbangkan sebisa mungkin dan reduksi lebih lanjut } \\
\text { mungkin tidak diperlukan. Jika resiko tersebut dapat } \\
\text { diselesaikan dengan cepat dan efisien, perhitungan } \\
\text { pengendalian harus diterapkan dan dicatat. }\end{array}$ \\
\hline
\end{tabular}

Sumber: Department of Occupational safety and Health Ministry of Human Resource Malaysia, 2008

Metode yang dipakai dalam analisis risiko adalah metode semikuantitatif. Analisis resiko mengeluarkan data dan informasi berupa nilai tingkat risiko (Risk Rate) yang nantinya akan diteruskan untuk mengevaluasi risiko dan penanganan terhadap risiko yang mungkin terjadi.
Perhitungan tingar resiko dapat dihitung dengan persamaan (1).

Tingkat Risiko $(\mathrm{RR})=(\mathrm{C}) \mathrm{x}(\mathrm{L})$

Dimana:

RR : Risk Rating (Tingkat risiko)

$\mathrm{C}$ : Consequence (Akibat) 


\section{L : Likelihood (Kemungkinan)}

Evaluasi risiko dilakukan untuk mencari solusi dan menentukan ketentuan yang akan dilakukan berdasarkan hasil analisis risiko yang di dapat, sehingga didapatkan prioritas pengendalian yang tepat dan sesuai. Dalam eveluasi risiko, nilai analisis risiko dibandingkan dengan Matriks Penilaian Tingkat Risiko yang dapat dilihat pada Tabel 3 dan Tabel 4, sehingga diketahui batasan risiko yang dapat diterima dan tidak dapat diterima Pengendalian risiko dilakukan terhadap seluruh bahaya yang ditemukan dalam proses identifikasi bahaya dan mempertimbangkan peringkat risiko untuk menentukan prioritas dan cara pengendaliannya. Dalam menentukan pengendalian harus mempertimbangkan hierarki pengendalian mulai dari eliminasi (menghilangkan suatu bahan/tahapan suatu proses berbahaya yang ada dalam perusahaan), substitusi(mengganti suatu bahan/peralatan untuk pengendalian proses berbahaya yang ada dalam perusahaan), rekayasa teknik (pemasangan atau pembuatan alat untuk pengendalian proses berbahaya demi keselamatan kerja karyawan), administrasi (cara yang administratif digunakan untuk pengendalian risiko berbahaya) dan penyediaan alat pelindung diri yang disesuaikan dengan kondisi organisasi, ketersediaan biaya, biaya personil, faktor manusia dan lingkungan.

\section{HASIL DAN PEMBAHASAN}

Hasil analisis identifikasi bahaya, penilaian resiko, pengendalian yang telah dilakukan perusahaan serta saran tambahan pengendalian resiko dapat dilihat pada Tabel 5. Adapun proses pada bagian produksi yang dianalisis pada penelitian ini adalah pada proses yang sering terjadi kecelakaan kerja. Proses tersebut terdiri dari mengolah raw material pada proses basah, penjemuran blanket, dan pengolahan blanket pada proses dryer bagian produksi PT X.

Tabel 5. Identifikasi Bahaya, Penilaian Resiko dan PengendalianResiko _pada Bagian Produksi PT X Menggunakan Metode HIRARC

\begin{tabular}{|c|c|c|c|c|c|c|c|c|c|}
\hline \multicolumn{4}{|c|}{ 1.Hazard Identification } & \multicolumn{5}{|c|}{ 2.Risk Analysis } & \multirow[b]{2}{*}{$\begin{array}{l}\text { Saran Sistem } \\
\text { Pengendalian }\end{array}$} \\
\hline $\begin{array}{l}\mathbf{N} \\
\mathbf{0}\end{array}$ & Proses & $\begin{array}{l}\text { Sumber } \\
\text { Bahaya } \\
(\text { Cause })\end{array}$ & $\begin{array}{c}\text { Jenis } \\
\text { Bahaya }\end{array}$ & $\begin{array}{c}\text { Pengendalian } \\
\text { Eksisting } \\
\text { (Action) } \\
\end{array}$ & $\mathbf{L}^{*}$ & $\mathbf{S}^{* * *}$ & $\mathbf{R} \mathbf{R} * *$ & $\begin{array}{l}\text { Skala } \\
\text { Resiko }\end{array}$ & \\
\hline \multirow[t]{5}{*}{1.} & \multirow[t]{5}{*}{$\begin{array}{l}\text { Mengolah } \\
\text { raw } \\
\text { material } \\
\text { di proses } \\
\text { basah }\end{array}$} & $\begin{array}{l}\text { Transfer } \\
\text { dengan } \\
\text { forklift }\end{array}$ & Tertabrak & $\begin{array}{l}\text { Driver berhati- } \\
\text { hati dalam } \\
\text { berkendara } \\
\text { dan melihat } \\
\text { kondisi sekitar }\end{array}$ & 3 & 1 & 3 & $\begin{array}{l}\text { Renda } \\
\mathrm{h}\end{array}$ & $\begin{array}{l}\text { Driver harus } \\
\text { dilakukan } \\
\text { pelatihan } \\
\text { terlebih dahulu }\end{array}$ \\
\hline & & Operator & $\begin{array}{l}\text { Tergelincir } \\
\text { Menghirup } \\
\text { bau }\end{array}$ & $\begin{array}{l}\text { Operator lebih } \\
\text { paham SOP }\end{array}$ & 4 & 2 & 8 & Sedang & $\begin{array}{l}\text { Penggunaan } \\
\text { alat pelindung } \\
\text { diri dalam } \\
\text { bekerja seperti } \\
\text { sepatu safety } \\
\text { dan masker }\end{array}$ \\
\hline & & $\begin{array}{l}\text { Pembongkara } \\
\mathrm{n}\end{array}$ & $\begin{array}{l}\text { Masuk ke } \\
\text { dalam } \\
\text { material }\end{array}$ & $\begin{array}{l}\text { Pekerja lebih } \\
\text { berhati-hati } \\
\text { dalam bekerja }\end{array}$ & 4 & 2 & 8 & Sedang & $\begin{array}{l}\text { Penggunaan } \\
\text { alat pelindung } \\
\text { diri dalam }\end{array}$ \\
\hline & & & Tergelincir & & & & & & $\begin{array}{l}\text { bekerja seperti } \\
\text { masker, sepatu }\end{array}$ \\
\hline & & & $\begin{array}{l}\text { Terkena alat } \\
\text { berat }\end{array}$ & & & & & & $\begin{array}{l}\text { safety dan } \\
\text { sarung tangan }\end{array}$ \\
\hline \multirow[t]{2}{*}{2.} & $\begin{array}{l}\text { Penjemura } \\
\mathrm{n} \text { blanket }\end{array}$ & $\begin{array}{l}\text { Kayu dan } \\
\text { karet kering }\end{array}$ & Kebakaran & $\begin{array}{l}\text { Pekerja lebih } \\
\text { berhati-hati } \\
\text { dalam } \\
\text { melakukan } \\
\text { perlakuan } \\
\text { terhadap } \\
\text { material yang } \\
\text { mudah } \\
\text { terbakar }\end{array}$ & 5 & 1 & 5 & Sedang & $\begin{array}{l}\text { Penyediaan } \\
\text { alat pemadam } \\
\text { kebakaran }\end{array}$ \\
\hline & & Penjemuran & Tergelincir & $\begin{array}{l}\text { Pekerja lebih } \\
\text { berhati-hati } \\
\text { dalam bekerja }\end{array}$ & 5 & 1 & 5 & Sedang & $\begin{array}{l}\text { Penggunaan } \\
\text { alat pelindung } \\
\text { diri dalam }\end{array}$ \\
\hline
\end{tabular}




\begin{tabular}{|c|c|c|c|c|c|c|c|c|c|}
\hline \multicolumn{4}{|c|}{ 1.Hazard Identification } & \multicolumn{5}{|c|}{ 2.Risk Analysis } & \multirow[b]{2}{*}{$\begin{array}{l}\text { Saran Sistem } \\
\text { Pengendalian }\end{array}$} \\
\hline $\begin{array}{l}\mathbf{N} \\
\mathbf{0}\end{array}$ & Proses & $\begin{array}{l}\text { Sumber } \\
\text { Bahaya } \\
\text { (Cause) } \\
\end{array}$ & $\begin{array}{c}\text { Jenis } \\
\text { Bahaya }\end{array}$ & $\begin{array}{c}\text { Pengendalian } \\
\text { Eksisting } \\
(\text { Action }) \\
\end{array}$ & $\mathbf{L}^{*}$ & $\mathbf{S} * *$ & $\mathbf{R R} * *$ & $\begin{array}{l}\text { Skala } \\
\text { Resiko }\end{array}$ & \\
\hline & & & & $\begin{array}{l}\text { seperti } \\
\text { mengecek } \\
\text { kondisi lantai }\end{array}$ & & & & & $\begin{array}{l}\text { berupa sepatu } \\
\text { safety dan } \\
\text { sarung tangan }\end{array}$ \\
\hline \multirow[t]{4}{*}{3.} & $\begin{array}{l}\text { Pengolaha } \\
\mathrm{n} \text { blanket } \\
\text { di dryer }\end{array}$ & Operator & $\begin{array}{l}\text { Tergelincir } \\
\text { Menghirup } \\
\text { bau }\end{array}$ & $\begin{array}{l}\text { Operator lebih } \\
\text { paham SOP }\end{array}$ & 4 & 2 & 8 & Sedang & $\begin{array}{l}\text { Penggunaan } \\
\text { alat pelindung } \\
\text { diri dalam } \\
\text { bekerja seperti } \\
\text { sepatu safety } \\
\text { dan masker }\end{array}$ \\
\hline & & Burner & Kebakaran & $\begin{array}{l}\text { Operator hati- } \\
\text { hati dalam } \\
\text { penggunaan } \\
\text { alat dan } \\
\text { memahami } \\
\text { SOP }\end{array}$ & 5 & 1 & 5 & Sedang & $\begin{array}{l}\text { Penyediaan } \\
\text { alat pemadam } \\
\text { kebakaran }\end{array}$ \\
\hline & & Press & $\begin{array}{l}\text { Tangan } \\
\text { terkena alat } \\
\text { press }\end{array}$ & $\begin{array}{l}\text { Pekerja lebih } \\
\text { hati-hati dalam } \\
\text { melakukan } \\
\text { proses } \\
\text { pengepresan }\end{array}$ & 5 & 1 & 5 & Sedang & $\begin{array}{l}\text { Pemberian } \\
\text { informasi } \\
\text { mengenai tata } \\
\text { cara dalam } \\
\text { melakukan } \\
\text { kegiatan pres } \\
\text { kepada } \\
\text { karyawan }\end{array}$ \\
\hline & & $\begin{array}{l}\text { Transfer } \\
\text { dengan } \\
\text { forklift }\end{array}$ & $\begin{array}{l}\text { Menabrak } \\
\text { pekerja lain } \\
\text { Forklift } \\
\text { terjatuh jika } \\
\text { beban } \\
\text { terlalu berat }\end{array}$ & $\begin{array}{l}\text { Driver berhati- } \\
\text { hati dalam } \\
\text { mengendarai } \\
\text { forklift }\end{array}$ & 3 & 1 & 3 & $\begin{array}{l}\text { Renda } \\
\mathrm{h}\end{array}$ & $\begin{array}{l}\text { Driver harus } \\
\text { melakukan } \\
\text { pelatihan serta } \\
\text { briefing } \\
\text { sebelum } \\
\text { bekerja }\end{array}$ \\
\hline
\end{tabular}

Keterangan:

* $\quad$ : Peluang (likelihood), **P: Tingkat keparahan (severity), ***R $\quad$ : Risk rate

Dari analisis penilaian resiko yang merupakan hasil perkalian peluang dan tingkat keparahan, tidak ditemukan proses yang memiliki tingkat resiko tinggi. Hanya ada dua pekerjaan dengan tingkat resiko rendah, yakni pada proses transfer dengan forklift pada pengolahan raw material dan pengolahan blanket di dryer. Sedangkan sisanya dari potensi bahaya yang ada memiliki tingkat resiko sedang.

Upaya pengendalian yang disarankan pada pengolahan raw material antara lain berupa penggunaan Alat Pelindung Diri (APD) bagi operator serta karyawan yang bekerja pada area pembongkaran. Sebaiknya perusahaan melengkapi APD untuk para pekerja, sesuai yang diatur dalam PP No. 50 Tahun 2012 dalam elemen keamanan bekerja berdasarkan SMK3.

Pada proses penjemuran blanket, perlu disediakan alat pemadam kebakaran pada tempat tumpukan kayu dan karet, karena berpotensi bahaya kebakaran, sedangkan pada proses penjemuran diharapkan karyawan selalu memakai sepatu safety agar dapat terhindar dari bahaya tergelincir. Selanjutnya pada bagian pengolahan blanket di dryer, operator disarankan memakai sepatu safety dan masker agar terhindar dari bahaya tergelincir dan menghirup bau tidak sedap, kemudian perlunya disediakan alat pemadam kebakaran pada pegoperasian burner, serta perlunya informasi tata cara kegiatan press agar tangan pekerja terhindar dari terkena alat press.

Penilaian risiko pada PT X tergolong lebih rendah dibandingkan dengan studi yang dilakukan oleh Mitbasman (2017) tentang analisis risiko pekerjaan pada bagian produksi karet di PT BHB Kota Padang dengan Metode HIRARC, terdapat sumber bahaya berupa gancu, forklift, lantai, mesin produksi, troli, gerobak dan soda api dengan 14 risiko tinggi, 71 risiko sedang dan 1 risiko rendah. Hal ini dapat terjadi karena PT X telah melakukan penerapan Sistem Manajemen Keselamatan dan Kesehatan Kerja (SMK3) dengan kategori baik. 


\section{KESIMPULAN}

Dari hasil studi yang telah dilakukan, didapatkan beberapa penlilaian risiko pada bagian produksi yang banyak ditemukannya kecelakaan kerja yakni pada proses pengolahan bahan baku, penjemuran blanket dan pengolahan blanket di dryer, tidak ada yang memiliki risiko tinggi. Risiko rendah ditemukan pada kegiatan yang menggunakan forklift, sedangkan selebihnya potensi bahaya yang ditemukan memiliki tingkat resiko sedang.

Jenis pengendalian yang disarankan berupa rekayasa teknik berupa penyediaan alat pemadam kebakaran pada area/mesin yang memiliki bahaya kebakaran, dan pengendalian administratif seperti Pemberian informasi mengenai tata cara dalam melakukan kegiatan pres kepada karyawan dan pelatihan karyawan serta pemakaian APD.

\section{DAFTAR PUSTAKA}

Budiono, AM. Sugeng, dan Pusparini, A. 2003. Keselamatan Kerja dan Pencegahan Kecelakaan Kerja. Bunga Rampai Hiperkes dan Keselamatan Kerja. Edisi ke-2. Semarang, Universitas Diponegoro
Department of Occupational safety and Health Ministry of Human Resource Malaysia. 2008. Guidelines for Harzard Identification, Risk Assessment and Risk Control (HIRARC).

Ihsan, T., Edwin, T., Irawan, R.O. 2016. Analisis Risiko K3 dengan Metode HIRARC pada Area Produksi PT Cahaya Murni Andalas Permai. Jurnal Kesehatan Masyarakat Andalas, Volume 10 Edisi (2), pp 179-185. Availabe online at http://jurnal.fkm.unand.ac.id/index.php/jkma/art icle/view/204/218

Mitsbasman, M. 2017. Analisis Risiko Pekerjaan Pada Bagian Produksi Dengan Metode HIRARC Di Perusahaan Karet PT BHB Kota Padang Tahun 2017. Tesis Fakultas Kesehatan Masyarakat. Available online at http://scholar.unand.ac.id/id/eprint/26209

Peraturan Pemerintah Nomor 50 Tahun 2012. Penerapan Sistem Manajemen Keselamatan dan Kesehatan Kerja. Jakarta.

Ramli, S. 2013. Sistem Managemen Keselamatan dan Kesehatan Kerja OHSAS 18001. Jakarta: PT Dian Rakyat.

Silalahi. 1991. Manajemen Keselamatan dan Kesehatan Kerja. Jakarta: PT. Pustaka Binaman Pressindo. Sucipto. 2014. Keselamatan dan Kesehatan Kerja. Yogyakarta: Gosyen Publishing.

Suma'mur. 2013. Higiene Perusahaan dan Kesehatan Kerja. Jakarta: Sagung Seto. 